\title{
Aerobic Microbiological Surveillance of Operation Theatre from a Tertiary Care Hospital, Kolhapur, India
}

\author{
Roma A. Chougale and P. Arun Kumar*
}

Department of Microbiology, D.Y Patil Medical College, Kolhapur, India

*Corresponding author

\section{A B S T R A C T}

Keywords

Settle plate method, Operation theatre, Antibiotic resistant, Surveillance

Article Info

Accepted:

10 September 2019

Available Online:

10 October 2019
Microbial contamination of operation theatres is the major cause of morbidity and mortality in post operative cases. The present study is to evaluate the microbial contamination of operation theatre and their antibiotic resistance pattern. This study was carried out from July 2018 to December 2018. Surface and article swabs were collected by using sterile cotton swabs moistened with nutrient broth and air samples were taken by settle plate method. All the samples were processed by standard microbiological procedure. A total of 1330 samples were collected of these $142(10.67 \%)$ were culture positive. Of these, Gram positive cocci $(52.11 \%)$ were isolated more followed by gram negative bacilli $(30.89 \%)$ and gram positive bacilli (16.90\%). Most of the tested antibiotic showed resistant to one antibiotic class $(45.07 \%)$ followed by two $(10.56 \%)$ and three antibiotic classes $(2.81 \%)$. Regular microbiological surveillance and frequent infection control audit reduce the microbial burdens and antibiotic resistant.

\section{Introduction}

Hospital acquired or nosocomial infection is the major cause of morbidity and mortality in post-operative cases and intensive care unit (ICU) patients. In hospital environment, microbial contamination is increasing nowadays and plays an important source of infection for their prevalence of HAIs ${ }^{1}$.

Invasive procedures in operating theatres, with judicious use of high antibiotic doses, allows transmission of microbes to patients indirectly via doctors or nurses due to lack of proper infection control measures. This plays a major role in emergence of antibiotic resistance and has been increasingly risky to patients during their hospital stay ${ }^{2}$.

Microbial contamination in the operation theatre is generally associated with a risk of post operative surgical site infection (SSI). It is the second most common cause after the urinary tract infection in hospitals. It is caused by endogenous microbial flora or exogenous microbial flora (OT environments) ${ }^{3}$. Evaluation of quality of air and various surface swabs for microbial counting and proper infection control management plays a crucial role in the control of post operative SSIs in hospitals and prevent extended patient stay in hospitals for treatment ${ }^{4}$. The aim of the 
present study is to evaluate the prevalence of microbial load and its antibiotic resistances pattern in the operation theatres in a tertiary care teaching hospital, Kolhapur.

\section{Materials and Methods}

The study was conducted in the department of the Microbiology, D.Y. Patil Hospital and Research Institute, Kolhapur, Maharashtra, India.

\section{Exclusion criteria}

Operation theatres kept open, overcrowded, dirty operation theatres with visible objects, and blood spillage during sampling were excluded in this study.

Study period: January 2018 to December 2018.

Air samples were taken by using Settle-plate method and $1 \mathrm{~cm}$ by $1 \mathrm{~cm}$. area/ $/ \mathrm{cm}^{2} /$ surface samples (Floor, Door, Trolley, machines, A/C, Lamp, Operating table etc.) were taken by using sterile cotton swabs and inoculated immediately into sterile nutrient broth, labeled properly and transported into the laboratory (Table 1).

\section{Air samples}

Three blood agar plates (100mm diameter) were taken for each OT with known surface area such as OT table at a height of 1 meter above the ground and corners of the operation theater ( 1 blood agar plate near the door and one near the washing area).

All plates were uncovered and exposed for 20 to 30 minutes. After 30 minutes, plates were closed, transported to the Microbiology laboratory and incubated at $37^{\circ} \mathrm{C}$ for 24 hours. After incubation, colonies on each blood agar plate were counted by using the following formula ${ }^{5}$ :
$N=5 \mathrm{a}^{*} 10^{4}(\mathrm{bt})^{-1}$

Where,

$\mathrm{a}=$ the number of colonies on the petri plate,

$b=$ the surface measurement of the of the plate used in $\mathrm{cm}^{2}$,

$\mathrm{t}=$ the time of exposure of the petri plate in minutes.

Recommended conventional microbial load values in Operation Theatre are as follows:

1. In an empty operation theatre it should not exceed $35 \mathrm{cfu} / \mathrm{m}^{3}$

2. During an operation, it should not exceed $180 \mathrm{cfu} / \mathrm{m}^{3}$

3. In ultra clean operating theatres where cardiac and joint replacement surgeries are performed, it should be less than 1 $\mathrm{cfu} / \mathrm{m}^{35}$

Surface swabs were taken from different areas by using sterile cotton swabs and streaked into Blood agar and MacConkey agar plates. The culture plates were incubated at $37 \mathrm{C}$ for 24 hours.

The isolates obtained were sub-cultured on MacConkey agar and Blood agar for further identification. Biochemical tests were performed for bacterial identification ${ }^{6}$ and antibiotic susceptibility test was performed by using Kirby- Bauer disc diffusion method, according to CLSI guidelines ${ }^{7}$.

\section{Results and Discussion}

A total of 1330 samples were collected. Of these, 142(10.67\%) samples were culture positive [48 from settle plate and 94 from surface and articles] and 1188 (89.32\%) were culture negative. 
Table.1 OT wise distribution of total positive cultures

\begin{tabular}{|c|c|c|}
\hline OT & $\begin{array}{c}\text { Swabs collected for } \\
\text { aerobic identification }\end{array}$ & $\begin{array}{c}\text { No. of aerobic } \\
\text { Culture } \\
\text { positive }\end{array}$ \\
\hline General OT & 158 & $18(12.67 \%)$ \\
\hline Orthopedics OT & 148 & $27(19.02 \%)$ \\
\hline Gynecology OT & 214 & $58(40.84 \%)$ \\
\hline Ophthalmology OT & 174 & $21(14.80 \%)$ \\
\hline ENT OT & 156 & $18(12.67 \%)$ \\
\hline Total & 850 & 142 \\
\hline
\end{tabular}

Table. 2 Total distribution of bacterial isolates $(n=142)$

\begin{tabular}{|l|l|l|l|l|l|l|l|}
\hline OT & $\begin{array}{l}\text { CONs } \\
(\mathbf{n = 4 1})\end{array}$ & $\begin{array}{l}\text { Micrococ } \\
\text { cus spp } \\
(\mathbf{n = 1 8})\end{array}$ & $\begin{array}{l}\text { S.aureus } \\
(\mathbf{n = 1 5})\end{array}$ & $\begin{array}{l}\text { Pseudomonas } \\
\text { spp } \\
(\mathbf{n = 1 2})\end{array}$ & $\begin{array}{l}\text { E.coli } \\
(\mathbf{n = 2 3})\end{array}$ & $\begin{array}{l}\text { Klebsiella } \\
\text { spp }(\mathbf{n = 9})\end{array}$ & $\begin{array}{l}\text { Bacillus } \\
\text { spp } \\
(\mathbf{n}=\mathbf{2 4})\end{array}$ \\
\hline General OT & $4(9.75 \%)$ & $3(16.66 \%)$ & $1(6.66 \%)$ & $2(16.66 \%)$ & $8(34.78 \%)$ & $2(22.22 \%)$ & $4(16.66 \%)$ \\
\hline Orthopedics OT & $6(14.63 \%)$ & $3(16.66 \%)$ & $4(26.66 \%)$ & $3(25 \%)$ & $6(26.08 \%)$ & $2(22.22 \%)$ & $5(20.83 \%)$ \\
\hline Gynecology OT & $23(56.09 \%)$ & $8(44.44 \%)$ & $5(33.33 \%)$ & $5(41.66 \%)$ & $7(30.43 \%)$ & $3(33.33 \%)$ & $8(33.33 \%)$ \\
\hline Ophthalmology OT & $4(9.75 \%)$ & $2(11.11 \%)$ & $3(20 \%)$ & $1(8.33 \%)$ & $3(13.04 \%)$ & $1(11.11 \%)$ & $3(12.5 \%)$ \\
\hline ENT OT & $4(9.75 \%)$ & $2(11.11 \%)$ & $2(13.33 \%)$ & $1(8.33 \%)$ & $2(8.69 \%)$ & $1(11.11 \%)$ & $4(16.66 \%)$ \\
\hline
\end{tabular}

Table.3 Antibiotic susceptibility testing for aerobic isolates [ $\mathrm{N}=142]$

\begin{tabular}{|l|l|l|l|l|l|l|l|}
\hline \multirow{2}{*}{ Antibiotic } & $\begin{array}{l}\text { CONS } \\
(\mathbf{n = 4 1})\end{array}$ & $\begin{array}{l}\text { Micrococc } \\
\text { us }(\mathbf{n = 1 8})\end{array}$ & $\begin{array}{l}\text { S.aureus } \\
(\mathbf{n = 1 5})\end{array}$ & $\begin{array}{l}\text { Pseudomonas } \\
(\mathbf{n = 1 2})\end{array}$ & $\begin{array}{l}\text { E.coli } \\
(\mathbf{n = 2 3})\end{array}$ & $\begin{array}{l}\text { Klebsiella } \\
(\mathbf{n = 9})\end{array}$ & $\begin{array}{l}\text { Bacillus spp } \\
(\mathbf{n}=\mathbf{2 4})\end{array}$ \\
\cline { 2 - 7 } & $\mathbf{R}$ & $\mathbf{R}$ & $\mathbf{R}$ & $\mathbf{R}$ & $\mathbf{R}$ & $\mathbf{R}$ & $\mathbf{R}$ \\
\hline Amoxicillin & $11(26.82 \%)$ & $08(44.44 \%)$ & $4(22.22 \%)$ & $\mathbf{I R}$ & $16(69.56 \%)$ & $\mathbf{5 ( 5 5 . 5 5 \% )}$ & $16(66.66 \%)$ \\
\hline Co-trimoxazole & $9(21.95 \%)$ & $06(33.33 \%)$ & $6(33.33 \%)$ & $6(50 \%)$ & $15(65.21 \%)$ & $4(44.44 \%)$ & $12(50 \%)$ \\
\hline $\begin{array}{l}\text { Piperacillin- } \\
\text { Tazobactum }\end{array}$ & $6(14.63 \%)$ & $06(33.33 \%)$ & $3(16.66 \%)$ & $3(25 \%)$ & $13(56.52 \%)$ & $4(44.44 \%)$ & $19(79.16 \%)$ \\
\hline Tobramycin & $4(9.75 \%)$ & $07(38.88 \%)$ & $2(11.11 \%)$ & $4(33.33 \%)$ & $13(56.52 \%)$ & $4(44.44 \%)$ & $17(70.83 \%)$ \\
\hline Ciprofloxacin & $8(19.51 \%)$ & $09(50 \%)$ & $4(22.22 \%)$ & $3(25 \%)$ & $16(69.56 \%)$ & $6(66.66 \%)$ & $13(54.16 \%)$ \\
\hline Gentamycin & $14(34.14 \%)$ & $08(44.44 \%)$ & $3(16.66 \%)$ & $4(33.33 \%)$ & $15(65.21 \%)$ & $3(33.33 \%)$ & $14(58.33 \%)$ \\
\hline Levofloxacin & $11(26.82 \%)$ & $06(33.33 \%)$ & $1(5.55 \%)$ & $3(25 \%)$ & $14(60.86 \%)$ & $3(33.33 \%)$ & $15(62.50 \%)$ \\
\hline Imipenem & $\mathrm{NA}$ & $06(33.33 \%)$ & $\mathrm{NA}$ & $4(33.33 \%)$ & $17(73.91 \%)$ & $6(66.66 \%)$ & $17(70.83 \%)$ \\
\hline Meropenem & $\mathrm{NA}$ & $05(27.77 \%)$ & $\mathrm{NA}$ & $5(41.66 \%)$ & $6(26.08 \%)$ & $2(44.44 \%)$ & $16(66.66 \%)$ \\
\hline Erythromycin & $21(51.21 \%)$ & $11(61.11 \%)$ & $7(38.88 \%)$ & $\mathrm{NA}$ & $\mathrm{NA}$ & NA & NA \\
\hline Tetracycline & $24(58.53 \%)$ & $09(50 \%)$ & $8(44.44 \%)$ & $5(41.66 \%)$ & $17(73.91 \%)$ & $7(77.77 \%)$ & NA \\
\hline Clindamycin & $11(26.82 \%)$ & $10(55.55 \%)$ & $4(22.22 \%)$ & NA & NA & NA & NA \\
\hline Doxycycline & $9(21.95 \%)$ & $6(33.33 \%)$ & $2(11.11 \%)$ & NA & NA & NA & NA \\
\hline Linezolid & $2(4.87 \%)$ & $3(16.66 \%)$ & 0 & NA & NA & NA & NA \\
\hline Chloramphenicol & $14(34.14 \%)$ & $11(61.11 \%)$ & $3(16.6 \%)$ & $4(33.33 \%)$ & $17(73.91 \%)$ & $5(55.55 \%)$ & $21(87.5 \%)$ \\
\hline
\end{tabular}


Table.4 Antibiotic susceptibility pattern for different antibiotic classes

\begin{tabular}{|c|c|c|c|}
\hline Organisms & $\begin{array}{c}\text { Resistance to one } \\
\text { antibiotic class }\end{array}$ & $\begin{array}{c}\text { Resistance to two } \\
\text { antibiotic class }\end{array}$ & $\begin{array}{c}\text { Resistance to three or } \\
\text { more antibiotic class }\end{array}$ \\
\hline CONS $(\mathbf{n}=\mathbf{4 1})$ & $18(12.67 \%)$ & $3(2.75 \%)$ & 0 \\
\hline Micrococcus $(\boldsymbol{n}=\mathbf{1 8})$ & $8(5.63 \%)$ & $2(1.40 \%)$ & 0 \\
\hline S. aureus $(\boldsymbol{n}=\mathbf{1 8 )}$ & $6(4.22 \%)$ & $2(1.40 \%)$ & $1(0.70 \%)$ \\
\hline Pseudomonas $\boldsymbol{s p p}(\boldsymbol{n}=\mathbf{1 2})$ & $4(2.81 \%)$ & $2(1.40 \%)$ & $1(0.70 \%)$ \\
\hline E.coli $(\boldsymbol{n}=\mathbf{2 3})$ & $12(8.54 \%)$ & $4(2.81 \%)$ & $1(0.70 \%)$ \\
\hline Klebsiella $(\boldsymbol{n}=\mathbf{9})$ & $4(2.81 \%)$ & $1(0.70 \%)$ & $1(0.70 \%)$ \\
\hline Bacillus $\boldsymbol{s p p}(\boldsymbol{n}=\mathbf{2 4})$ & $12(8.54 \%)$ & $1(0.70 \%)$ & 0 \\
\hline Total & $64(45.07 \%)$ & $15(10.56 \%)$ & $4(2.81 \%)$ \\
\hline
\end{tabular}

Fio 31. Distribution of Samnles $(\mathrm{N}=1330)$

culture positive

$89 \%$

culture negative

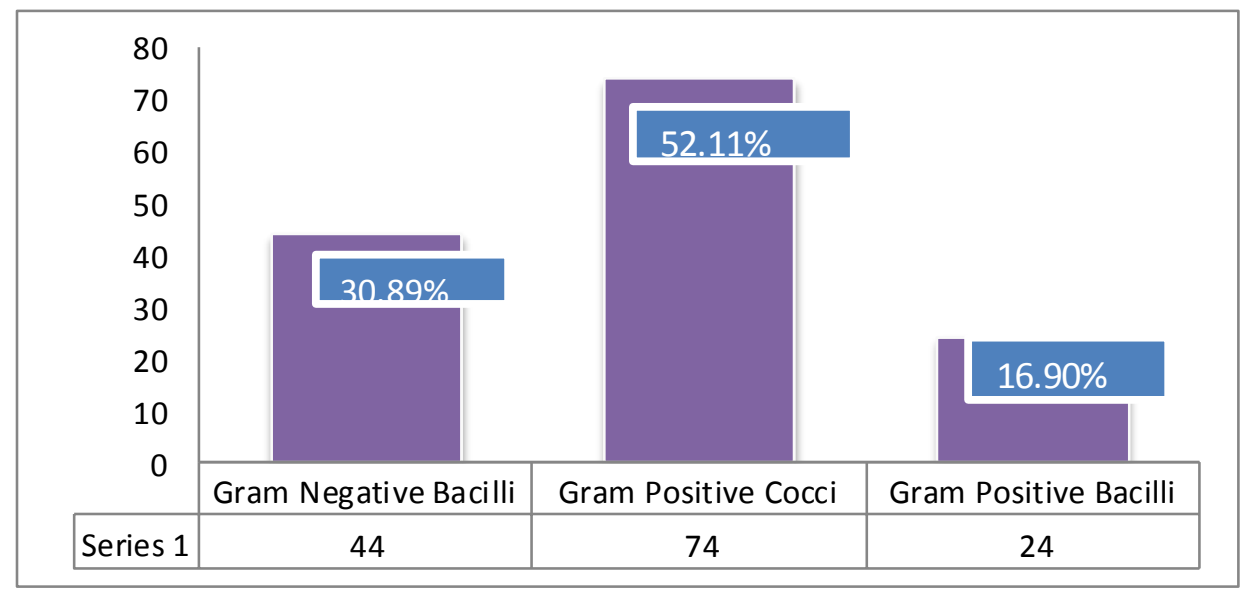

Post-operative surgical site infection is a major cause of patient morbidity and mortality in the hospitals. Environmental contamination of hospital promotes prolonged stay of the patients in hospitals. This creates long term disabilities, developing unwanted antimicrobial resistance, massive increase in the financial burden of patients and health care facilities leading to unnecessary deaths. 
Well- implemented hospital infection control program in hospitals will improve the education and accountability of the health care workers. Apart from this, it is necessary to conduct frequent audits and surveillance to validate the hospital infection rate; and implement the necessary action to prevent the hospital acquired infections ${ }^{8}$.

In our study, $142(10.67 \%)$ were culture positive. The prevalence of aerobic isolates from other studies shows variations ranging from $3.7 \%$ to $39.6 \%{ }^{9,10}$ (Hailu Getachew 2018, S.Ensayef,) this variation may be due to the condition of the hospital, duration of the study and time of sample collection (Example: whether it is collected during operation or after operation without cleaning the OT).

In this study, $30.89 \%$ were gram negative bacilli, $52.11 \%$ were gram positive cocci and $16.90 \%$ were gram positive bacilli. This finding of higher rate of gram positive organisms is comparable to Alkali Mohammed et al., $2017^{11}$ who showed more gram positive bacteria than gram negative. The high rate of gram-positive isolates in OT may be due to the environmental condition of the OT such as drier condition, contamination of healthcare workers (Skin, Nose and Boils etc.) and the type of surgery undergone in $\mathrm{OT}^{12}$.

In the present study, maximum number (36.36\%) of CONs were isolated, followed by Bacillus spp (17.27\%), Micrococcus (13.63\%), S. aureus (13.63\%), Pseudomonas (8.18\%), E.coli (8.27\%), Klebsiella spp $(3.63 \%)$ (Table 2). This is probably due to the healthcare workers' frequent entry into OT without any proper protective equipments and handling of instruments without any gloves after fumigation. All these isolates are well known to cause nosocomial infections in surgical ward and immuno- suppressed patients. The number of bacteria isolated varied in different hospital environments ${ }^{13}$.

Less than $50 \%$ of gram positive and $70 \%$ gram negative isolates showed resistance to commonly used antibiotics. This resistance rate is lower than the other studies showed by Hailu Getachew et al., 2018 (more than 80\%).

$45.07 \%$ isolates showed resistant to one antibiotic class, $10.56 \%$ isolates showed resistance to two antibiotic class and $2.81 \%$ isolates showed resistance to more than 3 or 4 antibiotic classes. This is lower than the other study conducted by Tesfaye et al., 2015 $(36.5 \%)^{14}$ isolates showed MDR positive. This could be due to over usage of the broad spectrum antibiotics in emergency situation and lack of awareness about hospital infection control policy (Table 3 and 4).

\section{Limitation}

In this study, we studied only aerobic identification; we have not assessed fungal and anaerobic bacterial isolates. Only a few antibiotics were tested against the isolated aerobic bacteria and they were not screened for MRSA, ESBL etc. We have not screened for antibiotic resistance among operation theatre healthcare workers. Because of the limited variables, we could not determine the possible associated factors that may contribute to the bacterial load in the operation theatre.

\section{References}

1. Kirkland KB. The impact of surgical-site infections in the 1990's: attributable mortality, excess length of hospitalization and extra costs. Infect Control Hosp Epidemiol 1999; 20: $725-$ 730.

2. Monika Yadav, Rohan Pal, Somorjit H. Sharma, Sulochana D. Khumanthem. 
"Microbiological surveillance of operation theatre in a tertiary care hospital in North East India". Int J Res Med Sci. 2017 Aug; 5(8):3448-3453

3. Dipender Kaur Najotra, Aneeta Singh Malhotra, Poonam Slathia, Shivani Raina, and Ashok Dhar "Microbiological Surveillance of Operation Theatres: Five Year Retrospective Analysis from a Tertiary Care Hospital in North India”. Int J Appl Basic Med Res. 2017 Jul-Sep; 7(3): 165-168.

4. Anjali K, Anamika V, Mrithunjay K, Dalal AS, Kumar A. Environmental microbiological surveillance of operation theatres in a tertiary care hospital. Int J Curr Res. 2015; 7: 13977-80.

5. Fleischer M, Bober-Gheek B, Bortkiewicz O, Rusiecka-Ziolkowskaa J. Microbiological control of airborne contamination in hospitals. Indoor and Built Environment. 2006; 15(1):53-6.

6. Patrica M. Tille Bailey and Scott's Diagnostic Microbiology. $13^{\text {th }}$ ed. St. Louis: Elsevier: 2007:197-231.

7. Clinical and Laboratory Standard Institute guideline: Performance standard for antimicrobial susceptibility testing: Wayne, PA-17 the informational supplement; 2018:M100-S17.

8. Kallel H, Bahoul M, Ksibi H, Dammak $\mathrm{H}$, Chelly H, Hamida CB, et al., Prevalence of hospital-acquired infection in a Tunisian hospital. J Hosp Infect. 2005; 59: 343-7.
9. Hailu Getachew, Awoke Derbie, and Daniel Mekonnen "Surfaces and Air Bacteriology of Selected Wards at a Referral Hospital, Northwest Ethiopia: A Cross-Sectional Study" International Journal of Microbiology Volume 2018; 1-7

10. Ensayef, S., Al Shalchi, S. and Sabbar, M. (2009). Microbial contamination in the operating theatre: a study in a hospital in Baghdad. EMHJ - Eastern Mediterranean Health Journal, 15 (1), 219-223, 2009

11. Alkali Mohammed et al., "Bacterial Contamination of Operating Theatres at A Tertiary Hospital in Bauchi, Northatsern Nigeria". ejpmr, 2017,4(4), 182-188

12. Sandra Matinyi et al., "Contamination of microbial pathogens and their antimicrobial pattern in operating theatres of peri-urban eastern Uganda: across-sectional study" BMC Infectious Diseases (2018) 18:460

13. Matinyi et al., "Contamination of microbial pathogens and their antimicrobial pattern in operating theatres of peri-urban eastern Uganda: a cross-sectional study" BMC Infectious Diseases (2018) 18:460

14. Tewelde Tesfaye, Yibrah Berhe, Kibrom Gebreselassie "Microbial contamination of operating Theatre at Ayder Referral Hospital, Northern Ethiopia" IJPSR Vol 6 No 10 Oct 2015.

\section{How to cite this article:}

Roma A. Chougale and Arun Kumar, P. 2019. Aerobic Microbiological Surveillance of Operation Theatre from a Tertiary Care Hospital, Kolhapur, India. Int.J.Curr.Microbiol.App.Sci. 8(10): 1210-1215. doi: https://doi.org/10.20546/ijcmas.2019.810.142 